\title{
DEVELOPMENT AND VALIDATION OF LC-MS/MS METHOD FOR ESTIMATION OF UROCARB IN HUMAN PLASMA
}

\section{IRYNA DRAPAK ${ }^{1}$, BORYS ZIMENKOVSKY ${ }^{2}$, LINA PEREKHODA ${ }^{3}$, SERGIY KOVALENKO4 ${ }^{4}$, LILIYA LOGOYDA ${ }^{*}$}

${ }^{1}$ General, Bioinorganic, Physical and Colloidal Chemistry Department, Danylo Halytsky Lviv National Medical University, Lviv City, Ukraine, ${ }^{2}$ Pharmaceutical, Organic and Bioorganic Chemistry Department, Danylo Halytsky Lviv National Medical University, Lviv City, Ukraine, ${ }^{3}$ Medicinal Chemistry Department, National University of Pharmacy, Kharkiv City, Ukraine, ${ }^{4}$ Organic and Bioorganic Chemistry Department, Zaporizhzhya State Medical University, Zaporizhzhya City, Ukraine, ${ }^{5}$ Pharmaceutical Chemistry Department, Pharmaceutical Faculty, I. Horbachevsky Ternopil State Medical University, Ternopil City, Ukraine Email: logojda@tdmu.edu.ua

Received: 30 Apr 2019, Revised and Accepted: 04 Jul 2019

\section{ABSTRACT}

Objective: The present study was aimed to develop a rapid, specific and sensitive method based on LC-MS/MS method was developed for the determination of urocarb using etomidate as an internal standard.

Methods: Chromatography was achieved on Discovery C18, $50 \times 2.1 \mathrm{~mm}, 5 \mu \mathrm{m}$ column. Samples were chromatographed in a gradient mode (eluent A (acetonitrile-water-formic acid, 5: 95: $0.1 \mathrm{v} / \mathrm{v}$ ), eluent B (acetonitrile-formic acid, 100: 0.1 v/v)). The initial content of the eluent B of 8\%, which increases linearly to $1.0 \mathrm{~min}$ to $100 \%$, is maintained up to $1.5 \mathrm{~min}$ and returned to the original $8 \%$ to $1.51 \mathrm{~min}$. The mobile phase was delivered at a flow rate of $0.400 \mathrm{ml} / \mathrm{min}$ into the mass spectrometer ESI chamber. The sample volume was $4 \mu \mathrm{l}$.

Results: The total chromatographic run time was $2.0 \mathrm{~min}$ and the elution of urocarb and IS (etomidate) occurred at $\sim 1.53$ and $1.67 \mathrm{~min}$, respectively. A linear response function was established at $1-100 \mathrm{ng} / \mathrm{ml}$ for urocarb and etomidate in human plasma. The $\%$ mean recovery for urocarb in LQC, MQC and HQC was $104.1 \%, 100.0 \%$ and $97.4 \%$. The lowest concentration with the RSD $20 \%$ was taken as LLOQ and was found to be $1.03 \mathrm{ng} / \mathrm{ml}$ for urocarb. The within-run coefficients of variation ranged between $0.271 \%$ and $0.478 \%$ for urocarb. The within-run percentages of nominal concentrations ranged between $99.12 \%$ and $100.21 \%$ for urocarb. The between-run coefficients of variation ranged between $0.388 \%$ and $0.601 \%$ for urocarb. The between-run percentages of nominal concentrations ranged between $98.78 \%$ and $101.11 \%$ for urocarb.

Conclusion: A highly sensitive, specific, reproducible, rapid and high-throughput LC-MS/MS assay was developed and validated to quantify urocarb in human plasma as per the regulatory guidelines. Due to the sensitivity of the developed method, it can be applied to the monitoring of plasma levels in the analysis of drug in preclinical and clinical pharmacokinetic studies. All the parameters and results were found within the acceptance limit as given in the validation protocol.

Keywords: LC-MS/MS, Urocarb, Human plasma, Validation, Pharmacokinetic studies

(c) 2019 The Authors. Published by Innovare Academic Sciences Pvt Ltd. This is an open-access article under the CC BY license (http://creativecommons.org/licenses/by/4.0/) DOI: http://dx.doi.org/10.22159/ijap.2019v11i5.33873

\section{INTRODUCTION}

The method development process can be broken down into components with a logical progression. In practice, the process is more a series of iterative and interlinked steps that may often need to be revisited and adjusted to finally arrive at the best method. Fully understanding these interdependencies and the requirements placed on the assay by these challenges leads to an assay that is fit for purpose [1].

Urocarb (fig. 1) (N-(5-Methyl-[1,3,4]thiadiazol-2-yl)-propionamide)the original newly synthesized diuretic, which increased daily diuresis in white rats, compared with intact controls, in 2.47 times, compared with with hydrochlorothiazide-in 1,6 times and acetazolamide-in 1,75 times [2]. When using urocarb, the main indicators of general urine analysis remained at the level of healthy, intact animals. However, there was a shift in the $\mathrm{pH}$ to the weaksided side-up to 8.3 units, which is a characteristic pharmacokinetic parameter for thiadiazole diuretics-carbonic anhydrase inhibitors [3]. The urine specimen of experimental animals in the introduction of urocarb was characterized by a significant increase in the allocation of $\mathrm{Na}+$ ions $(\mathrm{p} \leq 0,001)$ and $\mathrm{K}+(\mathrm{p} \leq 0,05)$ and statistically insignificant increase in the output of $\mathrm{Cl}$-ions. The level of excretion of these electrolytes exceeded the similar indices in the group of intact control, but qualitatively and favorably distinguished in relation to reference drugs, in particular, the lower level of removal of potassium and chloride ions. In this way, urocarb has a high diuretic effect and is a low-toxic and non-hepatotoxic compound. This implies the possibility of creating on its basis a new diuretic drug urocarb. This indicates the promise of this substance for further preclinical studies.<smiles>CCC(=O)Nc1nnc(C)s1</smiles>

Fig. 1: Chemical structure of urocarb

Urocarb is an original newly synthesized diuretic. Previously was no any bioanalytical method development for urocarb. Therefore, it was thought desirable to develop a simple, accurate and fast procedure that could be applied for the determination of urocarb in human plasma, this study performed assay validations as per guidelines [4-6].

\section{MATERIALS AND METHODS}

\section{Chemicals and reagents}

Urocarb (purity $98.8 \%$ ) was synthesized, etomidate (Internal Standard) (purity $98.9 \%$ ) was purchased from ANEK PRAYOG PVY. LTD. (Maharashtra, India), MOEHS CATALANA, S. L., (Barcelona, Spain), Zhejiang Huahai Pharmaceutical Co., Ltd (Zhejiang, China), EDQM-Council of Europe. HPLC grade acetonitrile and methanol were purchased from CHROMASOLV, HPLC grade formic acid was purchased from Fluka. All other chemicals and reagents were of analytical grade. Microcaps ${ }^{\circledR}$ disposable micropipettes $(50 \mu \mathrm{l}$, catalog number: 1-000-0500) were purchased from Drummond Scientific Company, USA. Ultra-pure water was obtained by using a MilliQ UF-Plus system (Millipore, Germany); resistivity $>18 \mathrm{M} \Omega . \mathrm{cm}^{-1}$ at $25{ }^{\circ} \mathrm{C}$ and $\mathrm{TOC}<5 \mathrm{ppb}$. The control of human dipotassium ethylenediaminetetraacetic acid ( $\left.\mathrm{K}_{2} \mathrm{EDTA}\right)$ plasma sample was procured from Red Cross Society, Ukraine. 


\section{Instrumentation and chromatographic conditions}

A Shimadzu HT (Shimadzu, Japan) LC system equipped with degasser (DGU-14A), binary pump (LC-20ADXR) along with autosampler (SIL-20AC HT) was used to inject $5 \mu \mathrm{l}$ aliquots of the processed samples on Discovery C18, $50 \times 2.1 \mathrm{~mm}, 5 \mu \mathrm{m}$ column maintained at $25 \pm 1{ }^{\circ} \mathrm{C}$. Samples were chromatographed in a gradient mode (eluent A (acetonitrile-water-formic acid, 5: 95: $0.1 \mathrm{v} / \mathrm{v}$ ), eluent B (acetonitrile-formic acid, 100: $0.1 \mathrm{v} / \mathrm{v}$ )) [7-8]. Samples were chromatographed in gradient mode. The initial content of the eluent $\mathrm{B}$ of $8 \%$, which increases linearly to $1.0 \mathrm{~min}$ to $100 \%$, is maintained up to $1.5 \mathrm{~min}$ and returned to the original $8 \%$ to 1.51 min (fig. 2). The mobile phase was delivered at a flow rate of 0.400 $\mathrm{ml} / \mathrm{min}$ into the mass spectrometer ESI chamber. Parameters of electrospray ionizer and MRM parameters are listed in table 1-2. The analytical data were processed by Analyst Software (version 1.5.2).

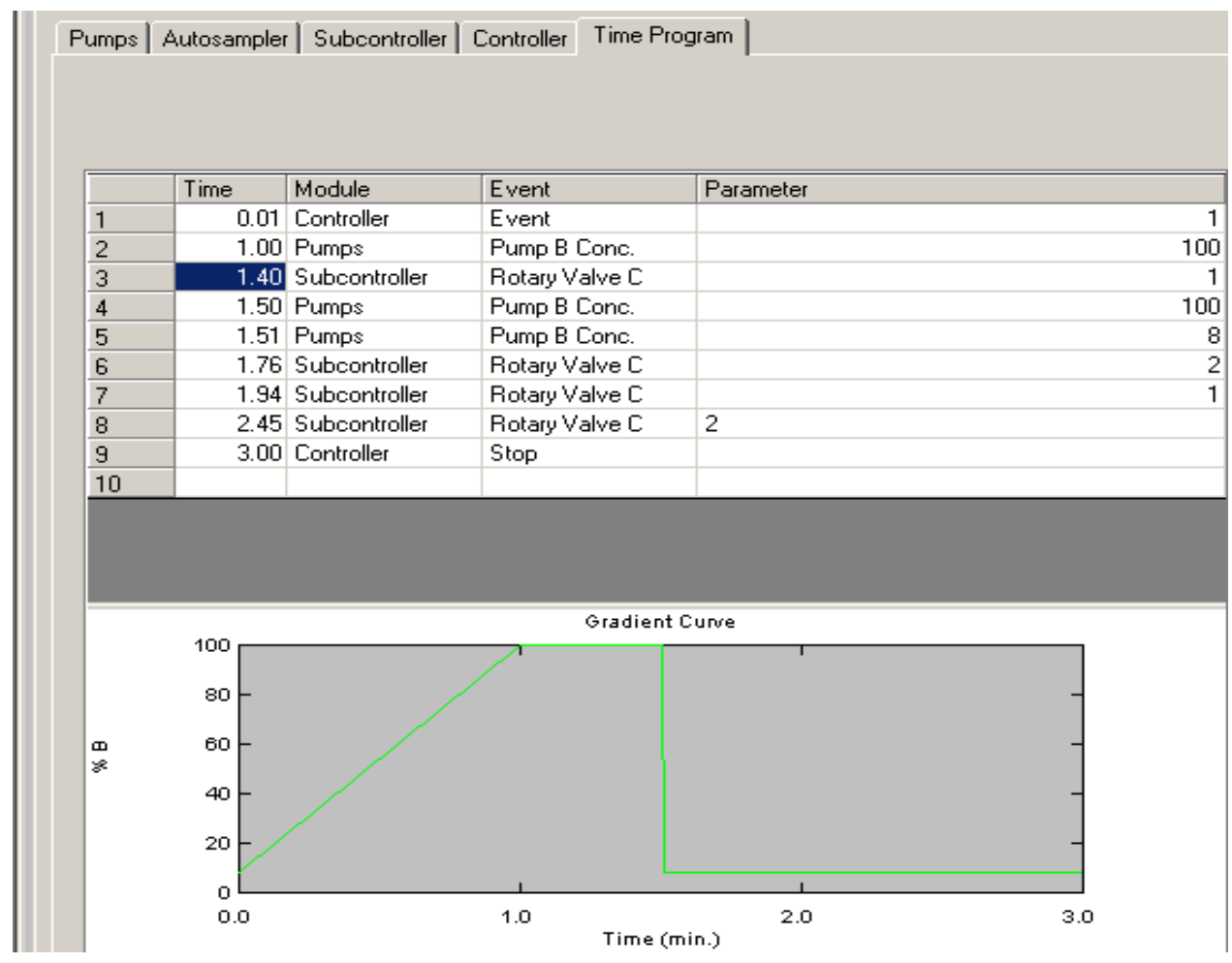

Fig. 2: Gradient mode

Table 1: Parameters of ionizer electrospray

\begin{tabular}{lll}
\hline S. No. & Parameter & Value \\
\hline 1 & Polarity & Positive \\
2 & Nebulizer Gas (NEB, Gas 1) & 15 \\
3 & Curtain Gas (CUR) & 8 \\
4 & Collision Gas (CAD) & 4 \\
5 & IonSpray Voltage (IS) & 5000 \\
6 & Temperature (TEM) & 400 \\
7 & Turbo IonSpray Gas & 8 \\
8 & Horizontal Position & 8.0 \\
9 & Lateral Position & 2.0 \\
\hline
\end{tabular}

Table 2: Multiple reaction monitoring (MRM) parameters

\begin{tabular}{|c|c|c|c|c|c|c|c|}
\hline ID & Parent, $\mathrm{m} / \mathrm{z}$ & Daughter, $\mathbf{m} / \mathbf{z}$ & Time, ms & DP, V & EP, V & CE, V & CXP, V \\
\hline Urocarb & 172.097 & 116.1 & 40 & 16 & 11 & 21 & 20 \\
\hline Etomidate & 245.308 & 141.2 & 40 & 71 & 11 & 15 & 12 \\
\hline
\end{tabular}

*Abbreviations: DP, declustering potential; FP, focusing potential; EP, entrance potential; CE, collision energy; CXP, collision cell exit potential

\section{Standard solutions}

Urocarb and IS were weighed accurately into volumetric flasks using an analytical microbalance. Approximately $1 \mathrm{mg} / \mathrm{ml}$ primary stock solutions of urocarb and $1 \mathrm{mg} / \mathrm{ml}$ primary stock solutions of etomidate (IS) solutions were prepared in methanol. The stock solutions were stored at $-20{ }^{\circ} \mathrm{C}$, which was found to be stable for 1 mo. The stock solutions of urocarb and etomidate were successively diluted with methanol and water to prepare secondary stocks and working solutions. Secondary stock solutions and working solutions were used to prepare calibration curve (CC) and quality control (QC) samples. Working stock solutions were stored at $4{ }^{\circ} \mathrm{C}$ for a week. Working stocks were used to prepare plasma calibration standards. A working IS solution $(25 \mathrm{ng} / \mathrm{ml})$ was prepared in acetonitrile: methanol (50:50 v/v). Blank human plasma was screened before spiking to ensure that it was free from endogenous interference at 
retention times of urocarb and etomidate, respectively. Calibration standards' samples (1-100 $\mathrm{ng} / \mathrm{ml}$ for urocarb and etomidate) were prepared by spiking the blank human $\mathrm{K}_{2}$ EDTA plasma with appropriate concentration of urocarb.

Samples for the determination of precision and accuracy were prepared by spiking control human plasma in bulk with urocarb at appropriate concentrations (for urocarb $3.00 \mathrm{ng} / \mathrm{ml}$ low QC [LQC], $30.00 \mathrm{ng} / \mathrm{ml}$ medium QC [MQC], and $75.00 \mathrm{ng} / \mathrm{ml}$ high QC [HQC]) and $120 \mu \mathrm{L}$ plasma aliquots were distributed into different tubes. All the samples were stored at $-80^{\circ} \mathrm{C} \pm 10^{\circ} \mathrm{C}$.

\section{Sample preparation}

A simple protein precipitation extraction method was followed for extraction of urocarb at from human plasma. From the deep freezer, the required quantities of CC standards and QC samples were with drawn. The samples were thawed at room temperature. To an aliquot of $100 \mu \mathrm{l}$ plasma, $20 \mu \mathrm{l}$ of IS was added. To this mixture, 300 $\mu \mathrm{l}$ of acetonitrile: methanol $(50: 50 \mathrm{v} / \mathrm{v})$ was added and vortexed for $2 \mathrm{~min}$, followed by centrifugation at $6000 \mathrm{rpm}$ for $5 \mathrm{~min}$ at $4{ }^{\circ} \mathrm{C}$. After centrifugation, approximately $50 \mu \mathrm{l}$ supernatant was aliquoted into, respectively, labeled autosampler vials, which were later placed in the autosampler at $15^{\circ} \mathrm{C} \pm 4^{\circ} \mathrm{C} .10 \mu \mathrm{l}$ of the sample was injected onto LC-MS/MS system for analysis.

\section{Method validation}

A full validation according to the ICH guidelines was performed for the assay in $\mathrm{K}_{2}$ EDTA human plasma [4].

\section{Specificity and selectivity}

The specificity of the method was evaluated by analyzing human plasma samples from different lots to investigate the potential interferences at the chromatographic peak region for urocarb and IS. The acceptance criterion for the experiment was that should have $<20 \%$ area response to that of the LLOQ level response in the same matrix. Two lots of hemolyzed plasma samples were also analyzed to ensure specificity against potential biological interferences.

\section{Linearity}

The points CC $(1-100 \mathrm{ng} / \mathrm{ml})$ were constructed by plotting the peak area ratio of analyte: IS against the nominal concentration of calibration standards in $\mathrm{K}_{2}$ EDTA human plasma. Following the evaluation of different weighing factors, the results were fit into linear regression analysis using $1 / \mathrm{X} 2$ (X: Concentration) weighing factor. The CC should have a correlation coefficient (r) of 0.99 or better. The acceptance criteria for each back-calculated standard concentration were $\pm 15 \%$ deviation from the nominal value except at LLOQ, which was set at $\pm 20 \%$.

\section{Recovery}

The efficiency of urocarb and IS extraction from human plasma was determined by comparing the responses of the analytes extracted from replicate $Q C$ samples $(n=6)$ with those of neat standard solutions spiked in post-extracted plasma blank sample at equivalent concentrations by protein precipitation extraction method. Recovery of urocarb was determined at LQC $(3.00 \mathrm{ng} / \mathrm{ml})$ and HQC $(75.00 \mathrm{ng} / \mathrm{ml})$ concentrations, whereas the recovery of IS was determined at a single concentration of $25 \mathrm{ng} / \mathrm{ml}$.

\section{Matrix effect}

The effect of human plasma constituents over the ionization of urocarb and IS was determined by post-column infusion method to evaluate matrix effect. Briefly, an infusion pump delivers a constant amount of analyte into LC system outlet entering to mass spectrometer inlet. To follow the analyte signal, the mass spectrometer was operated in MRM mode. The human plasma constituent sample extract was injected on LC column. A steady ion response was obtained as a function of time since the analyte was infused at a constant rate. Any endogenous compound that elutes from the column which causes a variation in ESI response of the infused analyte was seen as a suppression or enhancement in the response of the infused analyte. A separate experiment was performed with urocarb and IS solutions, which were infused at a constant rate, and blank matrix sample injected through the LC. To evaluate matrix effect, different lots of human plasma were spiked with analyte concentration levels at LQC and HQC levels. According to guidelines, the acceptance criterion for each back-calculated concentration was $\pm 15 \%$ deviation from the nominal value.

\section{Precision and accuracy}

The intra-assay precision and accuracy were estimated by analyzing six replicates containing urocarb at four different $\mathrm{QC}$ levels in human plasma. The four-level QC samples on four different runs were performed to assess the interassay precision. The acceptance criteria for each back-calculated standard concentration were 85$115 \%$ accuracy from the nominal value except at LLOQ, which was set at $80-120 \%$.

\section{Stability experiments}

Stability tests were conducted to evaluate the stability of urocarb in plasma samples under different conditions. $8 \mathrm{~h}$ bench top stability, processed samples stability (autosampler stability for $26 \mathrm{~h}$ at $10^{\circ} \mathrm{C}$ ), three cycles of freeze-thaw stability, $30 \mathrm{~d}$ of long-term stability at $-80 \pm 10{ }^{\circ} \mathrm{C}$ were performed at LQC and HQC levels using six replicates at each level. Samples were considered stable if assay values' acceptance criterion was of accuracy (i.e., $85-115 \%$ from fresh samples) and precision (i.e., $\pm 15 \%$ relative standard deviation [RSD]).

\section{RESULTS AND DISCUSSION}

Urocarb is original newly synthesized diuretic. Aim of our work was also to develop rapid, sensitive, and highly selective LCMS/MS method for urocarb. The purpose of sample extraction optimization is mainly to achieve high extraction recovery with negligible or low matrix effects to improve sensitivity and reliability of LC-MS/MS analysis [6-12]. A poor extraction procedure decreases method robustness due to the presence of endogenous interference in the sample extracts, which are not efficiently cleaned up due to poor extraction procedure decreases the method robustness due to the endogenous interference in the sample extracts. With time-saving advantage and simplicity, the protein precipitation extraction method was chosen as an extraction method. The attained LLOQ was sufficient to quantify urocarb in low-dose pharmacokinetic studies.

For LC system setup, mobile phase, LC column, gradient, flow rate, and column temperature are the most commonly adjusted factors based on method development time, analysis run time, and expected number of samples per day. The purpose of method development is to establish a fast, reliable method which can provide clear resolution of the analyte. For MS system setup, ion source parameters, mass transitions monitored in MRM, and collision cell parameters are commonly-adjusted factors based on expected analyte concentration and response. The goal of the adjustment is to optimize MRM transition response while remaining free of interference.

In the present study, optimization and critical evaluation of mobile phase composition (gradient), flow rate, and analytical column were important to obtain a good resolution of peaks of interest from the endogenous components, which in turn affect reproducibility and sensitivity of the method. Selection of chromatographic conditions for the proposed method was optimized to suit the preclinical pharmacokinetic studies. To ease the sample preparation in microtubes and to reduce the usage of solvent, the plasma volume was kept low. Initial feasibility experiments of a various mixture(s) of solvents such as acetonitrile, methanol and formic acid along with altered flow rates (in the range of 0.1-0.6 $\mathrm{ml} / \mathrm{min}$ ) were performed to optimize an effective chromatographic resolution of urocarb and IS. Various analytical columns were tested to obtained good and reproducible response within short run time. The resolution of peaks was best achieved with Discovery C18, $50 \times 2.1 \mathrm{~mm}, 5 \mu \mathrm{m}$ column. Samples were chromatographed in a gradient mode (eluent A (acetonitrile-water-formic acid, 5: 95: $0.1 \mathrm{v} / \mathrm{v}$ ), eluent B (acetonitrile-formic acid, 100: $0.1 \mathrm{v} / \mathrm{v}$ )). The initial content of the eluent $\mathrm{B}$ of $8 \%$, which increases linearly to $1.0 \mathrm{~min}$ to $100 \%$, is maintained up to $1.5 \mathrm{~min}$ and returned to the original $8 \%$ to 1.51 
$\min$. The mobile phase was delivered at a flow rate of $0.400 \mathrm{ml} / \mathrm{min}$ into the mass spectrometer ESI chamber. The injection volume was $4 \mu \mathrm{l}$.

Urocarb eluted at $\sim 1.53 \mathrm{~min}$, respectively. During a direct infusion experiment, the mass spectra for urocarb and IS revealed peaks at $\mathrm{m} / \mathrm{z} 172.097$ and 245.308, respectively as protonated molecular ions, $[\mathrm{M}+\mathrm{H}]+$. Typical multiple reaction monitoring chromatograms of urocarb and internal standard in dipotassium ethylenediaminetetraacetic acid human blank plasma are shown in fig. 3.

\section{Specificity}

Different lots of plasma were analysed to ensure that no endogenous interferences were present at the retention time of urocarb LLOQ level samples along with plasma blank from the respective plasma lots were prepared and analysed (table 3 ).

\section{Linearity}

The calibration standard curves had a reliable reproducibility over the standard concentrations across the calibration range. The average regression $(n=3)$ was found to be $>0.99$ for analyte.
Bl - DU (Blank) 172097/116.100 Da - sample 6 of 38 from Lin CP.DU 4ul 060319. Ares: 10 counts Height: $7.95 \mathrm{e}+000 \mathrm{cps}$ RT: $1.54 \mathrm{~min}$

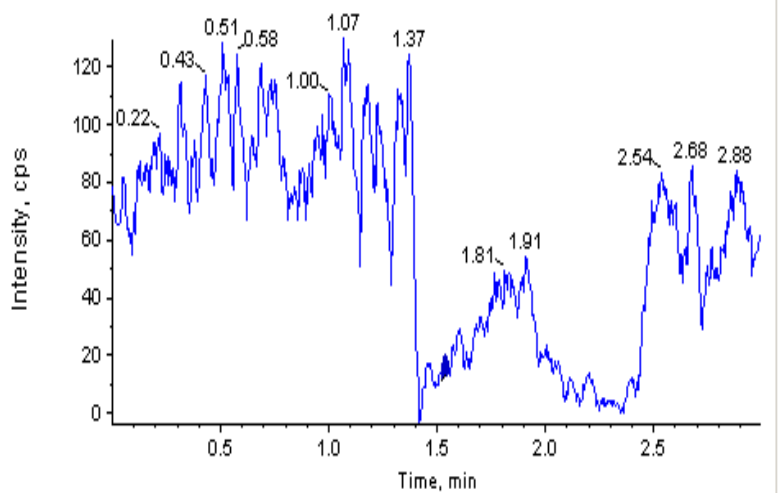

C1 · DU (Standard) $172.097 / 116.100 \mathrm{Da} \cdot$ sample 8 of 38 from Lin CP.DU 4Ul 060319.wiff Area: 430 counts Height: $1.36 \mathrm{e}+002$ ops RT: $1.53 \mathrm{~min}$

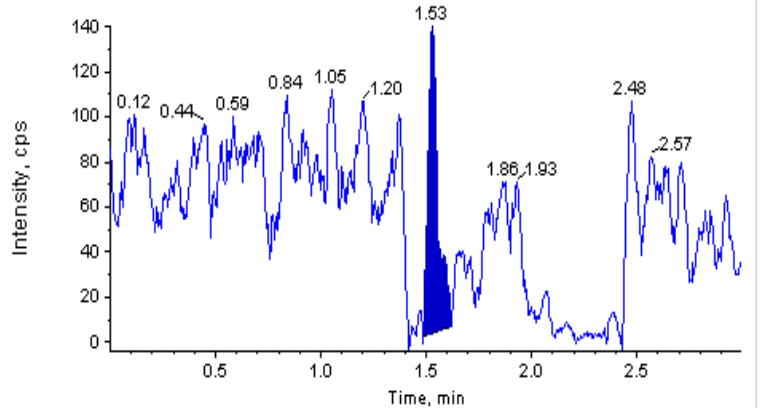

Bl - Em(IS) (Blank) 245.308/141.200 Da - sample 6 of 38 from Lin CP.DU 4ul 060319.wiff Area: 56 counts Height: $4.14 \mathrm{e}+001 \mathrm{cps}$ RT: $1.72 \mathrm{~min}$

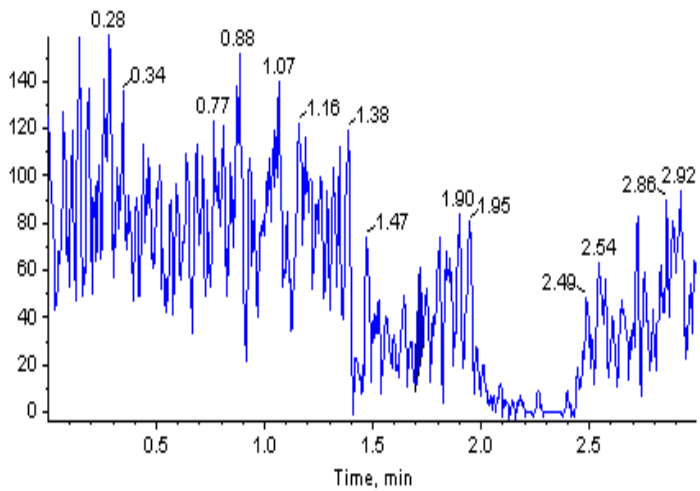

C1 - Em(IS) (Standard) $245.308 / 141.200 \mathrm{Da} \cdot$ sample 8 of 38 from Lin CP.DU 4 Ul 060319.wi Area: 100400 counts Height: $5.25 \mathrm{e}+004 \mathrm{cps}$ RT: $1.67 \mathrm{~min}$

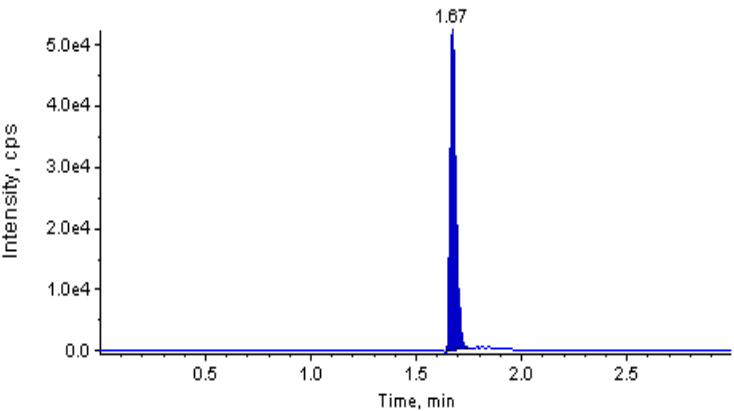

Fig. 3: Typical multiple reaction monitoring chromatograms of urocarb (left) and internal standard (etomidate) (right) in dipotassium ethylenediaminetetraacetic acid human blank plasma, The total chromatographic run time was 2.0 min and the elution of urocarb and IS (etomidate) occurred at $\sim 1.53$ and $1.67 \mathrm{~min}$, respectively

Table 3: Results of specificity for urocarb

\begin{tabular}{lllll}
\hline S. No. & Enalapril & & & \\
\cline { 2 - 4 } & STD BL & LLOQ & \% Interference \\
\cline { 2 - 4 } & & Area & RT & NIL \\
\hline 1 & 0 & 376 & 1.53 & NIL \\
2 & 0 & 457 & 1.52 & NIL \\
3 & 0 & 373 & 1.52 & NIL \\
4 & 0 & 457 & 1.53 & NIL \\
5 & 0 & 310 & 1.53 & NIL \\
6 & 0 & 467 & 1.53 & NIL \\
7 & 0 & 398 & 1.53 & NIL \\
8 & 0 & 412 & 1.53 & \\
9 & 0 & 451 & 1.52 & 1.53 \\
10 & 0 & 385 & & \\
\hline
\end{tabular}

*Average of triplicate injections, In all plasma blanks, the response at the retention time of urocarb was less than $20 \%$ of LLOQ response and at the retention time of IS, the response was less than $5 \%$ of mean IS response in LLOQ. 


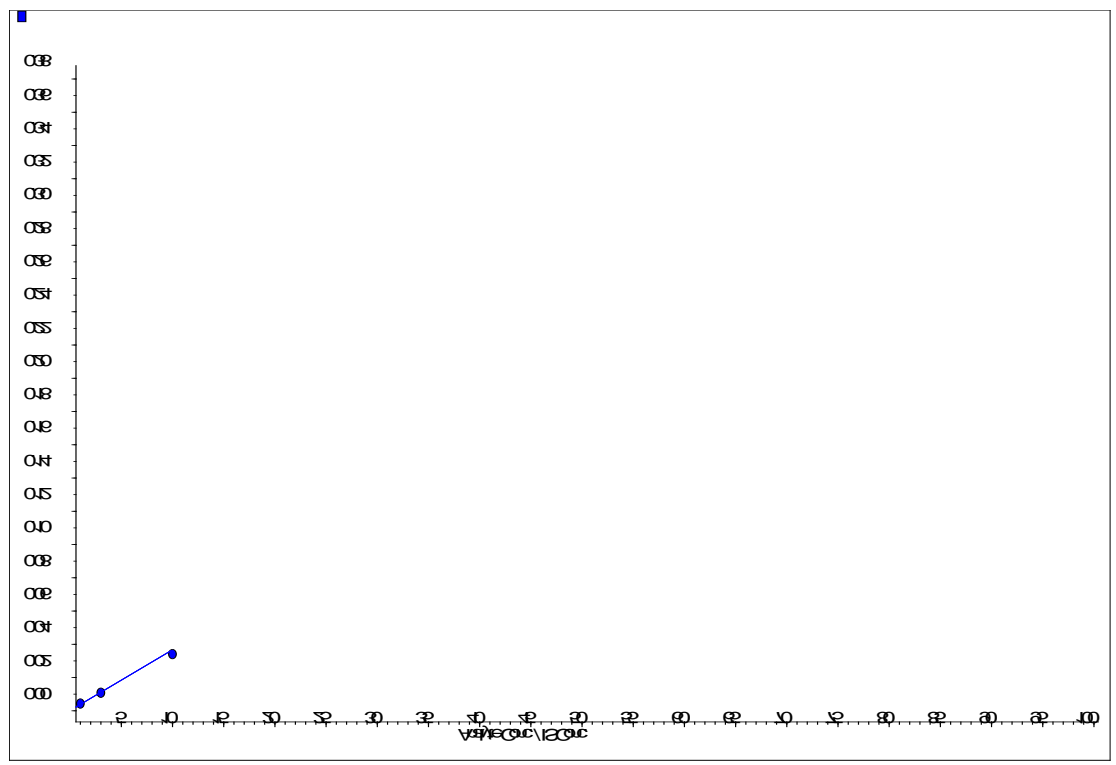

Fig. 4: The calibration curve of urocarb in human plasma

The calibration curve (fig. 4) (peak area ratio Vs Concentration) was linear over working range for urocarb of 1 to $100.00 \mathrm{ng} / \mathrm{ml}$ with 7 point calibration used for quantification by linear regression, shown in fig. 4. The regression equation for the analysis was $y=0.00365 x+0.000177$ with coefficient of correction (r2) $=0.9993$.

\section{Recovery}

The \% mean recovery for urocarb in LQC, MQC and HQC are listed in table 4 .

Table 4: The \% mean recovery of urocarb for LQC, MQC and HQC

\begin{tabular}{|c|c|c|c|}
\hline S. No. & LQC & MQC & HQC \\
\hline 1 & 3.28 & 30.2 & 73.5 \\
\hline 2 & 3.30 & 32.3 & 71.9 \\
\hline 3 & 2.72 & 28.4 & 72.3 \\
\hline 4 & 2.99 & 29.4 & 72.2 \\
\hline 5 & 3.32 & 29.8 & 75.2 \\
\hline Mean & 3.12 & 30.0 & 73.0 \\
\hline SD & 0.262 & 1.46 & 1.36 \\
\hline$\% \mathrm{CV}$ & 8.4 & 4.9 & 1.9 \\
\hline \% Mean Recovery & 104.1 & 100.0 & 97.4 \\
\hline
\end{tabular}

*Abbreviations: Lower quality control (LQC), middle-quality control (MQC), higher quality control (HQC)

Each value is represented as a mean $\pm S D$ of 5 observations $(n=5), S D$ : Standard Deviation, RSD: Relative Standard Deviation, \#Acceptance criteria $<15 \%$.

The \% mean recovery for urocarb in LQC, MQC and HQC was 104.1 $\%, 100.0 \%$ and $97.4 \%$.
Intraday (within run) and Inter-day (between run) precision and accuracy

The within-run coefficients of variation ranged between $0.271 \%$ and $0.478 \%$ for urocarb. The within-run percentages of nominal concentrations ranged between $99.12 \%$ and $100.21 \%$ for urocarb. The between-run coefficients of variation ranged between $0.388 \%$ and $0.601 \%$ for urocarb. The between-run percentages of nominal concentrations ranged between $98.78 \%$ and $101.11 \%$ for urocarb. Results are presented in table 5.

Table 5: Intra-day and Inter-day precision data of urocarb

\begin{tabular}{lllll}
\hline Day & Intra-day precision & & Inter-day precision & \\
\hline & Mean & R. S. D \% & Mean & R. S. D \% \\
\hline 1 & 99.12 & 0.271 & 101.11 & 0.412 \\
2 & 100.21 & 0.478 & 98.78 & 0.388 \\
3 & 100.18 & 0.367 & 100.93 & 0.601 \\
\hline
\end{tabular}

*Each value is represented as a mean \pm SD of observations, SD: Standard Deviation, RSD: Relative Standard Deviation, \#Acceptance criteria $<15 \%$., The assay values on both the occasions (intra-and inter-day) were found to be within the accepted limits.

\section{Matrix effect}

The lowest concentration with the RSD $<20 \%$ was taken as LLOQ and was found to be $1.03 \mathrm{ng} / \mathrm{ml}$ for urocarb. Results are presented in table 6.
*Abbreviations: Lower limit of quantification (LLOQ)

Each value is represented as a mean \pm SD of 5 observations $(n=5), S D$ : Standard Deviation, RSD: Relative Standard Deviation, \#Acceptance criteria< $20 \%$ 
The \% accuracy of LLOQ samples prepared with the different biological matrix lots was found $102.5 \%$, which were found within the range of $80.00-120.00 \%$ for the seven different plasma lots. $\%$ CV for LLOQ samples was observed as $15.2 \%$, which are within $20.00 \%$ of the acceptance criteria.

\section{Stability}

The predicted concentrations for urocarb $(3.00 \mathrm{ng} / \mathrm{ml}$ and 75.00 $\mathrm{ng} / \mathrm{ml}$ ) deviated within $\pm 15 \%$ of the fresh sample concentrations in a battery of stability tests namely, in-injector ( $22 \mathrm{~h})$, bench-top $(7 \mathrm{~h})$, and repeated four freeze/thaw cycles stability (table 7).

Table 6: Results of matrix effect of urocarb

\begin{tabular}{ll}
\hline S. No. & LLQC \\
\hline 1 & 0.985 \\
2 & 1.160 \\
3 & 0.980 \\
4 & 1.190 \\
5 & 0.808 \\
Mean & 1.03 \\
SD & 0.156 \\
\% CV & 15.2 \\
Mean Recovery & 102.5 \\
\hline
\end{tabular}

Table 7: Stability data of urocarb at QCs in human plasma

\begin{tabular}{|c|c|c|c|c|}
\hline \multirow[t]{2}{*}{ Nominal concentration $(\mathrm{ng} / \mathrm{ml})$} & \multirow{2}{*}{ Stability } & \multicolumn{3}{|l|}{ Stability data } \\
\hline & & Mean $\pm \operatorname{SD}^{\circ}(n=6)$ & Accuracy (\%)• & Precision (\% CV) \\
\hline \multirow[t]{4}{*}{ Urocarb-3.00 } & $0 \mathrm{~h}$ & $3.12 \pm 0.41$ & 99.1 & 2.56 \\
\hline & $7 \mathrm{~h}$ (bench-Top) & $3.11 \pm 0.32$ & 99.8 & 2.23 \\
\hline & $22 \mathrm{~h}$ (in-injector) & $3.05 \pm 0.31$ & 99.2 & 2.44 \\
\hline & 3 FT cycles & $3.09 \pm 0.26$ & 99.4 & 2.32 \\
\hline \multirow[t]{4}{*}{ Urocarb-75.00 } & $0 \mathrm{~h}$ & $75.8 \pm 0.41$ & 99.5 & 2.12 \\
\hline & $7 \mathrm{~h}$ (bench-Top) & $75.5 \pm 0.28$ & 99.1 & 2.55 \\
\hline & $22 \mathrm{~h}$ (in-injector) & $75.9 \pm 0.29$ & 99.3 & 2.27 \\
\hline & 3 FT cycles & $75.9 \pm 0.38$ & 99.4 & 3.01 \\
\hline
\end{tabular}

${ }^{\circ}$ Back-calculated plasma concentrations; •Mean assayed concentration/mean assayed concentration at $0 \mathrm{~h} \times 100$. FT: Freeze-thaw, SD: Standard deviation, QC: Quality control, The results were found to be within the assay variability limits during the entire process.

\section{CONCLUSION}

A highly sensitive, specific, reproducible, rapid and high-throughput LC-MS/MS assay was developed and validated to quantify urocarb in human plasma as per the regulatory guidelines. The present method involved a simple precipitation method of sample preparation, which gave consistent and reproducible recoveries. Acquired results demonstrate that proposed strategy can be effortlessly and advantageously applied for routine examination of urocarb in human plasma.

Due to the sensitivity of the developed method, it can be applied to the monitoring of plasma levels in the analysis of drug in preclinical and clinical pharmacokinetic studies. All the parameters and results were found within the acceptance limit as given in the validation protocol.

\section{AUTHORS CONTRIBUTION}

All the authors have contributed equally

\section{CONFLICT OF INTERESTSw}

The authors declare no conflict of interest

\section{REFERENCES}

1. https://www.waters.com/webassets/cms/library/docs/7200 02710en.pdf. [Last accessed on 10 Mar 2019]

2. Claudiu T Supuran, Andrea Scozzafava, Angela Casini. Carbonic anhydrase inhibitors. Med Res Rev 2002;2:146-89.

3. Drapak Iryna Syntesis. Diuretic activity research and QSARanalysis of $\mathrm{N}$-(1,3,4-thiadiazol-2-il)substituted amides of alkanecarboxylic acids. Farmatsevtychnyi zhurnal 2019;2:8093.
4. Guideline on Bioanalytical method validation: European Medicines Agencies; 2011.

5. Sonawane LV, Poul BN, Usnale SV. Bioanalytical method validation and its pharmaceutical application a review. Pharm Anal Acta 2014;5:1-7.

6. Pushpa Latha E, Sailaja B. Bioanalytical method development and validation by HPLC: a review. J Appl Pharm 2014;1:1-9.

7. Liliya Logoyda. Bioanalytical method development and validation from the simultaneous determination of verapamil and enalapril in the present of enalaprilat by HPLC MS/MS. Int J Appl Pharm 2018;10:19-27.

8. Liliya Logoyda. A HPLC-MS/MS method development and validation for the simultaneous determination of nifedipine and enalapril in human plasma. Int J Appl Pharm 2018;10:35-42.

9. Ghosh C, Jain I, Shinde CP, Chakraborty BS. Rapid and sensitive liquid chromatography/tandem mass spectrometry method for simultaneous determination of enalapril and its major metabolite enalaprilat, in human plasma: application to a bioequivalence study. Drug Testing Anal 2012;4:94-103.

10. Bhardwaj SP, Singh S. Study of forced degradation behavior of enalapril maleate by LC and LC-MS and development of a validated stability-indicating assay method. J Pharm Biomed Anal 2008;46:113-20.

11. Logoyda L, Kondratova Y, Korobko D, Susla O, Soroka Y, Tsytsiura R, Pidruchna S. Youden's test of the chromatographic determination of captopril in pharmaceuticals. Int J Green Pharm 2017;11:188-91.

12. Liliya Logoyda, Dmytro Korobko, Oleksandra Oleshchuk, Taras Proniv, Mariya Dmutriv. A HPLC MS/MS method development and validation for the simultaneous determination of bisoprolol and enalapril in the present of enalaprilat in human plasma. Int J Appl Pharm 2018;10:31-40. 